\title{
Estimated total emissions of trace gases from the Canberra Wildfires of 2003: a new method using satellite measurements of aerosol optical depth \& the MOZART chemical transport model
}

\author{
C. Paton-Walsh ${ }^{1}$, L. K. Emmons ${ }^{2}$, and S. R. Wilson ${ }^{1}$ \\ ${ }^{1}$ School of Chemistry, University of Wollongong, Wollongong, NSW 2522, Australia \\ ${ }^{2}$ National Center for Atmospheric Research, Boulder, Colorado, USA \\ Received: 2 October 2009 - Published in Atmos. Chem. Phys. Discuss.: 18 January 2010 \\ Revised: 22 June 2010 - Accepted: 23 June 2010 - Published: 30 June 2010
}

\begin{abstract}
In this paper we describe a new method for estimating trace gas emissions from large vegetation fires using satellite measurements of aerosol optical depth (AOD) at $550 \mathrm{~nm}$, combined with an atmospheric chemical transport model. The method uses a threshold value to screen out normal levels of AOD that may be caused by raised dust, sea salt aerosols or diffuse smoke transported from distant fires. Using this method we infer an estimated total emission of $15 \pm 5 \mathrm{Tg}$ of carbon monoxide, $0.05 \pm 0.02 \mathrm{Tg}$ of hydrogen cyanide, $0.11 \pm 0.03 \mathrm{Tg}$ of ammonia, $0.25 \pm 0.07 \mathrm{Tg}$ of formaldehyde, $0.03 \pm 0.01$ of acetylene, $0.10 \pm 0.03 \mathrm{Tg}$ of ethylene, $0.03 \pm 0.01 \mathrm{Tg}$ of ethane, $0.21 \pm 0.06 \mathrm{Tg}$ of formic acid and $0.28 \pm 0.09 \mathrm{Tg}$ of methanol released to the atmosphere from the Canberra fires of 2003. An assessment of the uncertainties in the new method is made and we show that our estimate agrees (within expected uncertainties) with estimates made using current conventional methods of multiplying together factors for the area burned, fuel load, the combustion efficiency and the emission factor for carbon monoxide. A simpler estimate derived directly from the satellite AOD measurements is also shown to be in agreement with conventional estimates, suggesting that the method may, under certain meteorological conditions, be applied without the complication of using a chemical transport model. The new method is suitable for estimating emissions from distinct large fire episodes and although it has some significant uncertainties, these are largely independent of the uncertainties inherent in conventional techniques. Thus we conclude that the new method is a useful additional tool for characterising emissions from vegetation fires.
\end{abstract}

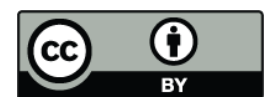

Correspondence to: C. Paton-Walsh (clarem@uow.edu.au)

\section{Introduction}

\subsection{Estimating fire emissions released to the atmosphere}

Vegetation fires are a major source of trace gases and aerosols to the atmosphere. Since fires are very variable in their frequency and extent, they constitute a large source of the variability in tropospheric composition. For this reason it is important to establish reliable means of estimating the emissions from biomass burning for use in atmospheric chemical transport models (Andreae and Merlet, 2001). Unfortunately there are large uncertainties in all available methods for estimating total emissions of trace gases and aerosols from fires. Estimates made using current conventional methods of multiplying together factors for the area burned, fuel load, the combustion efficiency and emission factors have shown poor agreement with estimates made using satellite measurements of carbon monoxide and inverse modelling techniques (Arellano et al., 2006; Hoelzemann et al., 2004). Thus any alternative method may be a useful additional tool for estimating emissions from vegetation fires and may also help elucidate the reasons for differences between existing methods.

\subsection{The Canberra Wildfires of 2003}

Abnormally high temperatures and low rainfall were experienced in south eastern Australia in the second half of 2002 due to a severe El Niño related drought that created conditions of extreme fire danger, with an abundance of dry fuel ready to burn. On 8 January 2003, fires were started by lightning strikes in the region around the Australian capital city of Canberra (35 S, 149E) and the nearby Snowy Mountains (Webb et al., 2004). The fires burned for several weeks, reaching their maximum intensity on January 18 when a firestorm engulfed several outer suburbs of Canberra. Four

Published by Copernicus Publications on behalf of the European Geosciences Union. 
people died and there was widespread damage to property including 491 houses lost. The fires also caused extensive damage to rural grazing property, forests and bushland in the area with substantial losses of farming stock and wildlife (Webb et al., 2004). At the peak of the firestorm on January 18 there were pyro-cumulonimbus eruptions that injected smoke plumes into the stratosphere (Fromm et al., 2006). The fires continued throughout January and well into February until they were eventually extinguished with the help of heavy rainfall towards the end of February 2003.

Smoke plumes from these fires passed over Wollongong (34 S, 151 E) and were measured by the remote sensing midinfrared and ultra-violet/visible spectrometers at the University of Wollongong (Paton-Walsh et al., 2004; Rinsland et al., 2005). Total column amounts of trace gases derived from these mid-infrared spectra showed very strong correlations with coincident and co-located measurements of aerosol optical depth at $500 \mathrm{~nm}$ (Paton-Walsh et al., 2005; Paton-Walsh et al., 2008). These strong correlations mean that it is possible to infer the enhanced column amount of a trace gas such as carbon monoxide (CO) that is present in an active fire region (whilst the smoke is still relatively young) using satellite measurements of enhanced aerosol optical depth (AOD) over the region. Summation of the inferred enhancements of trace gases on each day that the fires burned, forms the basis of a new method for estimating total emissions to the atmosphere from a major fire episode. The use of aerosol optical depth to infer the emissions of trace gases such as $\mathrm{CO}$ introduces additional uncertainties compared to studies that directly use satellite measurements of CO, e.g. (Pfister et al., 2005), however aerosol optical depth measurements typically have greater sensitivity to the boundary layer and thus may capture smoke that could be missed by satellite-based measurements of CO. Possibly a more significant advantage of using AOD as a proxy for $\mathrm{CO}$ in this method is the fact that aerosols are comparatively short-lived and so provide a better indication of fresh smoke emissions than the presence of enhanced amounts of relatively long lived trace gases such as $\mathrm{CO}$.

\subsection{MODIS measurements of AOD}

The Moderate Resolution Imaging Spectroradiometer, (MODIS) instruments provide high radiometric sensitivity in 36 spectral bands ranging in wavelength from $0.4 \mu \mathrm{m}$ to 14.4 $\mu \mathrm{m}$... (Kaufman, 1993;Kaufman et al., 2003;Kaufman et al., 1990; King et al., 1999; Remer et al., 2002;Zhao et al., 2003). They are carried on both the Terra and Aqua satellites (orbiting at an altitude of $705 \mathrm{~km}$ ), providing global coverage every 1 to 2 days with a swath that is $2,330-\mathrm{km}$ cross track by $10 \mathrm{~km}$ along the track at nadir. For most parts of the globe, including southeast Australia, twice daily coverage at local times of about 10:45 (Terra) and 14:00 (Aqua) is achieved. Each instrument contains a two-mirror off-axis collimating telescope, which collects radiant energy and directs it into four refractive objective assemblies, covering the visible, near infrared, short-wave to medium-wave infrared and long-wave infrared regions of the spectrum.

The MODIS instruments' products include visible images, aerosol optical depth (also called aerosol optical thickness) and thermal anomalies (pinpointing the locations of fires) (Kaufman et al., 1998). MODIS aerosol optical depth (product MOD 04) data are retrieved over the oceans globally and over large portions of the continents at the spatial resolution of $10 \times 10 \mathrm{~km}$ (Chu et al., 1998; Kaufman et al., 1997; Tanre et al., 1997). Separate algorithms are used to derive aerosol optical depth over sea and land, with recent work to optimise these algorithms including the deep-blue algorithm developed to derive aerosol optical thickness over bright land areas (Levy et al., 2007; Kleidman et al., 2005).

\subsection{Determining the increased atmospheric loading of carbon monoxide from the fires using MODIS aerosol optical depth measurements}

The enhanced column amounts of carbon monoxide that were present in the atmosphere in the region surrounding the Canberra fires of 2003 were inferred using the following steps:

\subsubsection{Step 1: average MODIS AOD data}

The Collection 5 MODIS aerosol product (MOD04 for Terra, MYD04 for Aqua) is used in this study. Specifically, we use the $10 \times 10 \mathrm{~km}^{2} 550 \mathrm{~nm}$ aerosol optical depth (AOD) retrieval from both land and ocean algorithms. For the period 7 January-26 February, 2003, and over south eastern Australia these retrievals were re-projected and plotted as a series of maps; one for each satellite overpass, giving two images per day. Many of the images have large amounts of missing data where the algorithms have rejected the data either as a result of cloud interference, sea-glint or other technical difficulties, resulting in interruptions in the twice daily timeseries. When one of the two images for the day showed a significantly clearer view of plumes from the fires, then only this image was used. Otherwise data from both images were combined. All aerosol optical depth values from the chosen images were averaged over $1^{\circ} \times 1^{\circ}$ grid boxes, extending from $-25^{\circ}$ to $-46^{\circ}$ latitude and $135^{\circ}$ to $160^{\circ}$ longitude. Example images are shown in Fig. 1.

\subsubsection{Step 2: determine background and threshold val- ues of AOD before the fires began}

The $1^{\circ}$ by $1^{\circ}$ averaged AOD data from the Aqua overpass from 7 January 2003 (the day before the fires started) were used to establish the normal levels of aerosol optical depth in the fire-affected area. There are sources of enhanced AOD other than fresh smoke from the active fires and so we must be careful not to overestimate the emissions by including AOD that results from dust, sea salt aerosols or aged smoke 

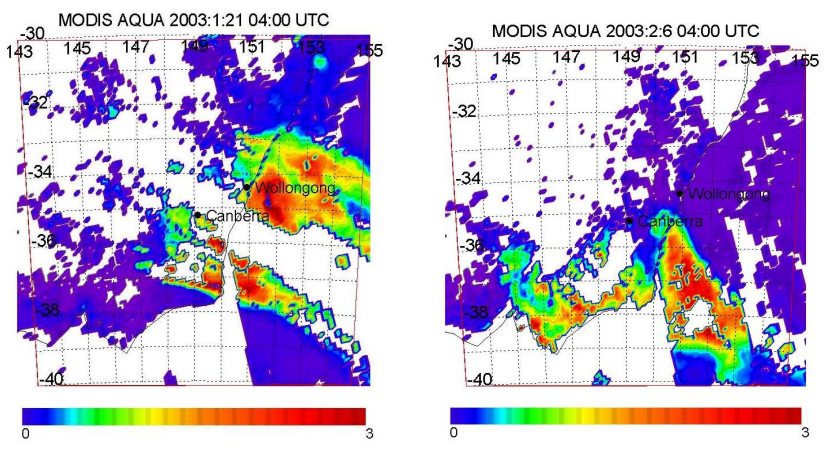

Fig. 1. Example images of MODIS product "MYD04" aerosol optical depth measurements over south-eastern Australia re-projected and plotted as maps. The Aqua overpass from 21 January 2003 is shown in the left-hand panel and the Aqua overpass from the 6th February is shown in the right-hand panel.

from other fires. For this reason we impose a threshold value that is set at the maximum AOD measured in the region before the start of the large vegetation fires. By excluding all grid boxes with AOD values no higher than the maximum measured before the fires, we expect to screen out all aerosol sources other than the fires.

Only $1^{\circ}$ by $1^{\circ}$ grid boxes with more that 10 points were considered because of the possibility of getting a few spuriously high points adjacent to points that are rejected by the MODIS algorithm due to cloud interference. The maximum AOD value for a $1^{\circ}$ by $1^{\circ}$ grid box on 7 January before the fires started was 0.2 , and so this was taken as a threshold value to identify fresh smoke. By excluding all values below this threshold we can avoid wrongly assigning a biomass burning emission to an enhancement in AOD that is caused by normal amounts of raised dust, sea salt aerosols or aged smoke. The mean AOD value for a $1^{\circ}$ by $1^{\circ}$ grid box on 7 January before the fires started was 0.11 and this was used as a "background" value $\left(\mathrm{AOD}_{b g}=0.11\right)$. In the subsequent days, whilst the fires burned, the excess AOD that resulted from fresh smoke from the active fires $\left(\mathrm{AOD}_{\text {excess }}\right)$ was estimated using Eq. (1).

For all $\mathrm{AOD}_{\mathrm{avg}}>0.2: \mathrm{AOD}_{\text {excess }}=\mathrm{AOD}_{\mathrm{avg}}-\mathrm{AOD}_{b g}$

where $\mathrm{AOD}_{\mathrm{avg}}=$ averaged $\mathrm{AOD}$ data in each $1^{\circ}$ by $1^{\circ}$ grid box.

\subsubsection{Convert enhanced AOD to enhanced mass of carbon monoxide}

The $1^{\circ}$ by $1^{\circ}$ averaged AOD excess values ( AOD $_{\text {excess }}$ ) were converted to equivalent enhanced carbon monoxide (CO) column amounts (molecules. $\mathrm{cm}^{-2}$ ) via the relationship $\mathrm{CO}=(1.5 \pm 0.1)$ AOD $\times 10^{18}$ molecules $\mathrm{cm}^{-2}$, as determined in Paton-Walsh et al [2005]. The enhanced CO column amounts were then converted to enhanced atmospheric loading of $\mathrm{CO}(\mathrm{g})$ by multiplying by the area of the $1^{\circ}$ by $1^{\circ}$ grid boxes (in square centimetres) and the molecular weight of $\mathrm{CO}$ and dividing by Avogadro's number.

The conversion is given by Eq. (2) below:

Equation 2:

$M_{\mathrm{CO}}=\frac{\mathrm{AOD}_{\text {excess }} \cdot G_{\mathrm{CO}: \mathrm{AOD}} A_{\text {grid }}}{N_{A}} \cdot M W_{\mathrm{CO}}$

Where

- $M_{\mathbf{C O}}=$ enhanced mass of CO in the region as a result of the fires

- AOD excess is 0.11 less than the $1^{\circ}$ by $1^{\circ}$ grid averaged MODIS AOD in each grid box that had a value above 0.2

- $\boldsymbol{G}_{\mathrm{CO}: \mathrm{AOD}}$ is $1.5 \times 10^{18}$ molecules $\mathrm{cm}^{-2}$ (the gradient of CO to AOD determined in Paton-Walsh et al., 2005)

- $\boldsymbol{A}_{\text {grid }}$ is $1.02 \times 10^{14}$ - the area of the grid boxes in $\mathrm{cm}^{2}$ using conversion factors of $111.12 \mathrm{~km}$ for $1^{\circ}$ latitude and $92.12 \mathrm{~km}$ for $1^{\circ}$ longitude

$-N_{\mathrm{A}}$ is Avogadro's Number $=6.02 \times 10^{23} \mathrm{~mol}^{-1}$ and

- $\boldsymbol{M} \boldsymbol{W}_{\mathbf{C O}}$ is the molecular weight of $\mathrm{CO}\left(28 \mathrm{~g} \mathrm{~mol}^{-1}\right)$

Finally summing the mass of enhanced CO in all the contributing grid boxes gives the total enhanced atmospheric mass of $\mathrm{CO}$ in the area on each day, (50 days from 8 January to 26 February 2003). Note that carbon monoxide is used here as an example and that the enhanced mass of any trace gas that is present in any large active fire region (for which there is a known strong correlation to AOD in young smoke plumes) may be inferred using the method outlined above.

\section{A new method for estimating trace gas emissions using MODIS aerosol optical depth measurements}

For every day from 8 January to 26 February 2003 the MODIS AOD measurements have yielded a daily value for the enhanced mass of $\mathrm{CO}$ over the defined fire region. A simple addition of these daily enhancements of $\mathrm{CO}$ yields a total amount of 12 teragrams ( $\mathrm{Tg}$ ) of $\mathrm{CO}$.

However smoke that remains in the defined region of interest for more than $24 \mathrm{~h}$ after being emitted by the fires has the potential to be detected by the MODIS AOD measurements from more than one satellite overpass. Thus the simple addition of daily enhancements in mass of $\mathrm{CO}$ may yield an overestimate of the emissions from the fires due to double counting of non-dispersed smoke. At the same time a significant amount of excess AOD may go undetected for a number of reasons including:

1. Smoke plumes may be mistaken as clouds and be thus removed from the final MODIS AOD product. 
2. Real clouds (either generated by the fires themselves or present in the region of the fires) cause interference with the retrieval of the MODIS AOD product and result in missing data.

3. The MODIS algorithm may reject data due to other interferences such as sea-glint.

4. Smoke may be transported out of the active region before it is detected by the overpassing satellite

This effect of missing enhanced AOD data will act to underestimate the total emission from the fires and so may counter-act the overestimate from double counting. However there is no reason why these two opposing effects should be of the same magnitude and so the sum of both is most probably not zero. However, a chemical transport model may be used to model the dispersion of the smoke plumes and estimate the amount of double counting.

\subsection{Modelling the dispersion of the smoke plumes}

An estimate of the $\mathrm{CO}$ that remained in the atmosphere from emissions from fires on previous days was made using the offline global chemical transport model MOZART-4 (Model of Ozone And Related Tracers-Version 4) (Emmons et al., 2010). The model was driven by meteorology from the NCAR reanalysis of the National Centers for Environmental Prediction (NCEP) forecasts (Kalnay et al., 1996) at a horizontal resolution of approximately $2.8^{\circ}$ by $2.8^{\circ}$, with 28 vertical levels from the surface to approximately $2 \mathrm{hPa}$.

The dispersion of the smoke plumes was modelled by a simple CO tracer simulation. The only emissions released in the model were $\mathrm{CO}$ emissions from the Canberra fires, with a separate tagged $\mathrm{CO}$ emission source defined for each day of the fires from 8 January to 26 February. The tagging of $\mathrm{CO}$ emissions for each day means that the model stores separate concentration fields for the $\mathrm{CO}$ that originated from each day of the fires. The locations of the fires were estimated from images of MODIS fire scars and thermal hotspots and then used to define the area over which the emissions were released into the model each day. In total seven $0.5^{\circ}$ by $0.5^{\circ}$ grid boxes were used as emission sources centred on the following coordinates: [35.5 S, 149.0 E], [36.0 S, 148.5 E], $[36.5 \mathrm{~S}, 148.5 \mathrm{E}],[37.0 \mathrm{~S}, 148.5 \mathrm{E}],[37.0 \mathrm{~S}, 148.0 \mathrm{E}]$, [37.0 S, 147.5 E], [37.0 S, 147.0 E]. The number of these grid boxes actually used as the source area for each day's emissions varied from only four to all seven, depending upon the location of the thermal hotspots detected that day. The flux rate for each tagged source was defined by releasing the total mass of enhanced CO (inferred from the AOD measurements from the relevant day) from the chosen source area at a uniform rate over the preceding $24 \mathrm{~h}$.

The model run started on 1 January 2003 and continued until 26 February with 48 individually tagged days of $\mathrm{CO}$ emissions. MOZART models the dispersion of the emitted
$\mathrm{CO}$ and the mass of each tagged $\mathrm{CO}$ source that remains in the defined region (from $-25^{\circ}$ to $-46^{\circ}$ latitude and $135^{\circ}$ to $160^{\circ}$ longitude) is extracted at 6-hourly intervals from the modelled concentration fields.

\subsection{Using the model output to correct for double- counting of the smoke}

In order to use the modelled $\mathrm{CO}$ concentration fields to adjust for double-counting of AOD in the smoke plumes we must impose a half-life characteristic of AOD to the modelled CO burden. The lifetime of aerosols in the atmosphere varies from seconds to days depending upon the size of the particles and the altitude that they are located, with lifetimes increasing for higher altitudes and for larger particles (on the sub-micron to nano-particle scale) (Williams et al., 2002). Thus the changing particle size distributions and plume heights for all the different smoke plumes emitted are not known. Instead, evidence is provided by satellite-based measurements of AOD made after the intense firestorms that burned across the Australian state of Victoria on 7 February 2009. AOD data from NASA's Ozone Monitoring Instrument (OMI) show that smoke from these intense fires separated from subsequent plumes and was transported to the north of New Zealand where it persisted for over a week before moving west across northern Australia and dissipating entirely over the Indian Ocean by early March (Young and PatonWalsh, 2010). This shows that smoke plumes from intense burning of eucalyptus trees (similar to the Canberra fires of 2003) produces plumes in which significant enhancements in AOD may persist for more than a week. Clearly it is usual for some proportion of smoke aerosols to persist for two or three weeks as plumes may be tracked by satellite measurements over such timescales e.g. (Radhi et al., 2009; Singh et al., 2006; Paton-Walsh et al., 2010).

Global model estimates for a lifetime of carbon aerosol of just under 5 days have been made by Rasch et al. (2000) and Chin et al. (2002), whilst Edwards et al. (2006a) use MODIS AOD and MOPITT CO measurements from the Terra satellite (Edwards et al., 2006b) to estimate a lifetime of $3.8 \pm 0.8$ days. This latter estimate was chosen as the most appropriate since it was based upon MODIS AOD measurements of smoke.

Thus the modelled $\mathrm{CO}$ concentration fields for all the tagged tracers were extracted for the time of each satellite overpass and a half-life of 3.8 days was applied the modelled burden of $\mathrm{CO}$. The inferred enhancement of atmospheric mass of $\mathrm{CO}$ on each day of the fires was adjusted to account for smoke emitted on earlier days. This was done by summing the tagged $\mathrm{CO}$ from all previous fire days that MOZART predicts will still be in the region for each $1^{\circ}$ by $1^{\circ}$ grid box that had an AOD $>0.2$ (and hence was included in the emissions calculation). The MOZART output grid is $2.8^{\circ}$ by $2.8^{\circ}$ and so only the appropriate proportion of the predicted $\mathrm{CO}$ burden in each modelled grid box is included as 
the double counting estimate for each $1^{\circ}$ by $1^{\circ}$ measurement grid box. The total estimated amount of double counting is then subtracted from the total enhanced $\mathrm{CO}$ in the region to yield the estimated fresh emissions during each day of the fires.

The process may be generalised by Eqs. (3) and (4):

$E_{\mathrm{CO}-\mathrm{day}_{n}}=M_{\mathrm{CO}-\mathrm{day}_{n}}-D C_{\mathrm{CO}-\mathrm{day}_{n}}$

where:

- $\boldsymbol{E}_{\mathrm{CO}-\mathrm{day}_{n}}=$ estimated mass of $\mathrm{CO}$ emitted by the fires during day $n$

- $\boldsymbol{M}_{\mathrm{CO}-\mathrm{day}_{n}}=$ enhanced mass of $\mathrm{CO}$ in the region after $n$ days of fires, inferred from the MODIS AOD measurements via Eq. (2)

- $\boldsymbol{D} \boldsymbol{C}_{\mathrm{CO}-\mathrm{day}_{n}}=$ estimated double counting of smoke on day $\mathrm{n}$

and where:

$D C_{\mathrm{CO}-\operatorname{day}_{n}}=\sum_{i=n}^{i=1}\left(\frac{E_{\mathrm{CO}-\mathrm{day}_{n-1}}}{M_{\mathrm{CO}-\mathrm{day}_{n-1}}} \cdot M R_{\mathrm{CO}_{\mathrm{tag}(n-i)}}\right)$.

where

- $\boldsymbol{M} \boldsymbol{R}_{\mathrm{CO}_{\operatorname{tag}(n-i)}}=$ the tagged mass of $\mathrm{CO}$ emitted on day $n-i$ that MOZART predicts still remains in the region at the time of the satellite overpass after day $n$

Note that the emissions must be calculated day by day, each time adjusting the emissions in the model to account for double-counting of smoke emitted on previous days.

As expected, the amount of double-counting predicted by the model is very variable from day to day as the meteorological conditions change. However the total amount doublecounting of previous emissions predicted by the model over the entire 50 day period is $20 \%$. Thus failing to account for the double-counting of smoke would have led to an overestimate of the total emissions of approximately $20 \%$.

\section{Uncertainties and biases in the method for estimating total emissions from fires}

Clearly there are a number of significant uncertainties in the method described here for estimating the total emissions of carbon monoxide (or other trace gases) from large-scale fires. There are uncertainties that pertain to correctly assigning the excess AOD that results from the fires and the degree of double-counting that occurs, but there are also uncertainties in the conversion from excess AOD to excess carbon monoxide. Many of the uncertainties inherent in this method are difficult to quantify because we do not have detailed knowledge of the true variance of the parameters. Despite this fact the exercise of constructing a full uncertainty budget can serve a useful purpose. Where there are no data on which to formally quantify the uncertainties we can make a reasonable guess that at the probable level of uncertainty in each component will not exceed half its value in the calculation. By this means it is possible to determine how the uncertainty propagates into the final uncertainty in total emissions. This allows us to make a very approximate estimate of the total uncertainties but also it can elucidate which components are likely to dominate the uncertainty budget.

\subsection{Uncertainties in determining the enhancements in AOD at $550 \mathrm{~nm}$ from the fires}

The major uncertainties in assigning the excess AOD from the fires come from undetected smoke and the choices of appropriate background and threshold AOD values. Undetected enhancements in AOD can result from smoke missed between clear satellite images or lost in the grid boxes with missing MODIS data leading to an underestimate of the emissions. If we make the assumption that the missing data are equally likely to contain smoke as the grid boxes with real MODIS AOD values, then we can estimate the magnitude of this uncertainty. The average percentage of grid boxes with missing data in the chosen daily images of the region around the Canberra fires is $34 \%$. If the undetected smoke is not dispersed from the region then it may be detected on subsequent days so the missing data count must be adjusted to account for this. The MOZART double counting estimate is $20 \%$, so the missing data count is multiplied by $80 \%$ to account for smoke that will not be detected on subsequent days. This gives a negative bias of $27 \%$ from smoke missed due to grid boxes with missing data, and we can make a guess as to the uncertainty in this number by assigning half this value, or approximately $\pm 14 \%$.

In reality the assumption that the missing data are equally likely to contain smoke enhanced AOD as the grid boxes with real AOD values may not be true, since the images were chosen from the Terra or Aqua data (or a combination of both) not randomly but depending upon which showed the clearest image of the smoke plumes. In addition intense firestorms (like the one that occurred on January 18 2003 near Canberra) can create cloud formations including pyro-cumulonimbus clouds that interfere with the satelliteinstrument's ability to detect the smoke clearly, resulting in missing data as the satellite's algorithm rejects the data. This effect is illustrated in Fig. 2 as significant amounts of smoke are visible to the eye in the MODIS true colour image (right-hand panel) but are missed by the MODIS AOD algorithm (left-hand panel). The amount of smoke missed in this manner is not easily quantifiable but unlikely to be a major factor in the uncertainty budget since these firestorms are unusual occurrences and the smoke may yet be detected in a subsequent satellite overpass. Future improvements in the algorithms for determining the AOD of the atmosphere from satellite-based instruments like MODIS may reduce the 


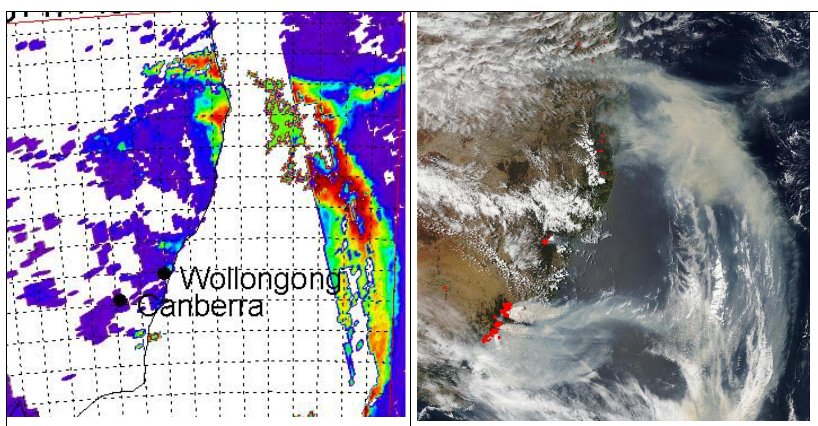

Fig. 2. Smoke plumes from the Canberra fires as seen from MODIS onboard the Aqua satellite on 18 January 2003. Left hand panel: MODIS Aerosol Optical Depth, Right-hand panel: (taken from http://rapidfire.sci.gsfc.nasa.gov/subsets/) MODIS true colour image with thermal anomalies shown as red pixels. Note that significant amounts of smoke visible to the eye in the right-hand panel are missed by the MODIS AOD algorithm.

fraction of missing data and improve the accuracy of this method (Remer et al., 2005).

The choice of the threshold and background values of AOD will also contribute to the uncertainties. The sensitivity of the estimated emissions to the choice of background value was estimated by using an AOD value of 0.2 for both the threshold value and the background value, which yielded a lower total emissions estimate by $20 \%$. A value of half this difference $( \pm 10 \%)$ is used as an estimated uncertainty that derives from the choice of background AOD value - an uncertainty that could be either positive or negative.

\subsection{Uncertainties in determining the amount of double-counting of smoke}

Errors in the MOZART modeling of the emission and dispersion of smoke from the fires may lead either to predicted double counting of smoke which in fact has been dispersed from the region, or to wrongly identifying fresh smoke as being from earlier emissions. Hence uncertainties in the dispersion modeling can lead to either underestimates or overestimates of emissions. In evaluation studies MOZART-4 modeled output has been shown to agree well with several independent sets of observations of tropospheric chemical composition (Emmons et al., 2010) but the modeling of the emissions from the Canberra fires in the model contains significant approximations and uncertainties. In particular the true fluxes of $\mathrm{CO}$ from individually detected fires is not known and is approximated in the model by a uniform emission at a constant flux rate from a small number of $0.5^{\circ}$ by $0.5^{\circ}$ grid boxes. These approximations will lead to uncertainties in the determination of the amount of smoke remaining to be double-counted. These uncertainties are extremely difficult to quantify but again we can see how the uncertainties propagate by assuming a figure of half the double-counting predic- tions of 20\% and thereby assigned an estimated uncertainty of $\pm 10 \%$ to this figure.

\subsection{Uncertainties in converting from excess AOD at $550 \mathrm{~nm}$ to excess carbon monoxide}

There is an uncertainty in the relationship established between ground-based sun-photometer measurements of AOD and column amounts of $\mathrm{CO}$ (of $\pm 7 \%$ ) as measured by PatonWalsh et al. (2005). In addition there are potential biases between ground-based sun-photometer AOD measurements and the $1^{\circ}$ by $1^{\circ}$ averaged AOD values from the MODIS instrument used in the conversion here. The viewing geometry of the two instruments differs and the satellite measurements are integrated over a large area at a single time whereas the ground-based measurements sample less than $1 \mathrm{~m}$ square but are averaged over several hours, therefore the values are only expected to be broadly comparable. There are only a few instances of highly elevated AOD from smoke plumes for which there are coincidental ground-based and satellitebased measurements from which a comparison may be made. Column $\mathrm{CO}$ amounts inferred from the MODIS AOD measurements using the nine closest $1^{\circ}$ by $1^{\circ}$ grid boxes to Wollongong compared to $\mathrm{CO}$ column amounts directly measured by ground-based Fourier transform spectrometry give a difference of $17 \% \pm 18 \%$ (Paton-Walsh et al., 2005). Direct comparison between ground-based AOD measurements from Wollongong and MODIS AOD for both the single $1^{\circ}$ by $1^{\circ}$ grid box over Wollongong and the 9 closest $1^{\circ}$ by $1^{\circ}$ grid boxes around Wollongong, indicates that the MODIS data are on average $27 \% \pm 23 \%$ lower than the equivalent groundbased data (Paton-Walsh et al., 2005). This could be caused by instrumental, analysis, local topographic or orographic differences, leading to a potential underestimate of the emissions. Note that the column CO agreement is better (in \% terms) because of the effect of adding in the background column of $1.5 \times 10^{18}$ molecules $\mathrm{cm}^{-2}$ of $\mathrm{CO}$, but that the actual AOD comparison is the most relevant to the calculation of uncertainties in the overall emissions estimate.

\subsection{Estimated total uncertainties in the method}

The uncertainties and biases in the method for using MODIS AOD to estimate total emissions of $\mathrm{CO}$ from the Canberra fires are summarised in Table 1. The final emissions estimate is corrected for all of the quantified biases, although the double-counting of smoke is done on a day by day basis whilst the other corrections are applied to the end result. Since there are no obvious correlations between the different components of the uncertainty budget our best method of estimating the total uncertainty is to add all component uncertainties in quadrature, yielding a value of $\pm 31 \%$. Note that the uncertainties in the conversion of sun-photometer measurements of AOD to column amounts of trace gases as measured by Paton-Walsh et al. (2005) vary from $\pm 3 \%$ to $\pm 8 \%$ 
Table 1. Biases and uncertainties in the method for estimating emissions of CO from the Canberra fires.

\begin{tabular}{lcc}
\hline Component of Uncertainty & Applied Correction to correct for Bias & Uncertainty \\
\hline MODIS missing data & $+27 \%$ & $\pm 14 \%$ \\
Background AOD & $\mathrm{n} / \mathrm{a}$ & $\pm 10 \%$ \\
Double-counting of smoke & (mean daily adjustment $=-20 \%)$ & $\pm 10 \%$ \\
Satellite AOD to sun-photometer AOD conversion & $+27 \%$ & $\pm 23 \%$ \\
Sun-photometer AOD to CO conversion & $\mathrm{n} / \mathrm{a}$ & $\pm 7 \%$ \\
\multicolumn{2}{c}{ Combined Total Uncertainty (added in quadrature) } & $\pm 31 \%$ \\
\hline
\end{tabular}

with the result that this component makes a very small contribution to the total uncertainty. This means that the combined total uncertainties in emissions from the fires of other gases with a known correlation with AOD will also be approximately $\pm 31 \%$.

In summary, there are some significant uncertainties and biases in the method described in this paper, but in most part the magnitude may be estimated and the biases corrected for. Although the estimate of the overall uncertainty is $\pm 31 \%$, current conventional methods of estimating emissions (Ito and Penner, 2004; Kasischke and Penner, 2004; Schultz et al., 2008; van der Werf et al., 2006) also suffer from large uncertainties, e.g. Schultz et al. quote an uncertainty in global direct carbon emissions for the 1980s and 1990s of $\pm 50 \%$ and for global $\mathrm{CO}$ emissions for the same time period of a factor of 2. Importantly, the uncertainties inherent in this study are mainly independent of the uncertainties in conventional methods of estimating emissions and so this new technique is a valuable additional tool for characterising emissions from large scale vegetation fires.

Note that this method is not applicable more generally to estimates of global emissions because it requires measurements of the large enhancements of aerosol optical depth that are associated with fresh smoke plumes (aged less than a couple of days) from large fire episodes. This ensures that the correlation with emitted trace gases is not compromised by aging of the plume and that (in the absence of another coincident major pollution event like a dust storm) the underlying variability in AOD from other aerosol sources will be too low to compromise the technique.

\section{Results of emissions estimate for the Canberra fires of 2003 and comparison to other inventories}

As mentioned above, a simple addition of the daily enhancements of $\mathrm{CO}$ inferred from MODIS AOD over the defined region around Canberra $\left(-25^{\circ}\right.$ to $-46^{\circ}$ latitude and $135^{\circ}$ to $160^{\circ}$ longitude) from 8 January to 26 February 2003 yields a total amount of $12 \mathrm{Tg}$ of CO. However, this figure does not include any correction for the bias in the satellite AOD to sun-photometer AOD conversion (quantified in Section 4.3). Correcting for this yields a value of $16 \mathrm{Tg}$ of $\mathrm{CO}$.
The combined effects of applying corrections for MOZART predictions for double-counting of smoke plumes and for missing data makes only a small difference reducing the value to $15 \mathrm{Tg}$ of $\mathrm{CO}$. Consideration of the total combined uncertainties gave us an estimate of $\pm 31 \%$ and so our final estimate for the emissions of $\mathrm{CO}$ from the Canberra fires of 2003 is $15 \pm 5 \mathrm{Tg}$ of $\mathrm{CO}$. It is worth noting that the combined effect of correcting for missing data and double-counting does not change the final emissions estimate significantly within the uncertainties of the calculation. This suggests the possibility of neglecting these complicated corrections and using instead a simple addition of the daily enhancements of trace gases inferred from MODIS AOD measurements. Judicial choice of the area over which the calculation is made can ensure that the typical meteorological conditions do not result in circulating wind fields that would lead to excessive double counting. The larger the region that is used the more likely an interfering pollution event will occur and the more likely that the meteorology will result in some smoke not being transported out between satellite overpasses. Thus the area chosen should be as small as possible whilst still containing the vast majority of the smoke emitted during the previous 24 hours. This simplified method assumes that to a first order approximation the effects of double-counting and missing data will approximately cancel.

Figure 3 is a bar chart showing each day's CO emissions alongside the modelled double counting for the day. Summing these two amounts gives the enhanced $\mathrm{CO}$ in the region from the fires derived from MODIS AOD data via Eqs. (1) and (2), corrected for the bias in the satellite AOD to sunphotometer AOD conversion. Also shown (on the right-hand axis) are the total accumulated emissions of $\mathrm{CO}$ from the fires.

The emissions predicted by the 8-day average GFED2 inventory (van der Werf et al., 2006) for the region from $25^{\circ}$ to $-46^{\circ}$ latitude and $135^{\circ}$ to $160^{\circ}$ longitude from 8 January to 26 February 2003 were extracted from the initial MOZART run described above, and gave a total emissions estimate of 13.0 Tg CO. It is possible that this emissions estimate could include other fires at the edge of the region chosen to encompass the smoke plumes from the Canberra fires. For this reason the 8-day average GFED2 inventory emissions were 
Table 2. Estimated total emissions from this study for the Canberra fires for all of the measured trace gases are shown in Tg and expressed as a percentage of the average global emissions from vegetation fires given in Schultz et al. (2008) for years 1960-1999.

\begin{tabular}{lccc}
\hline Gas & $\begin{array}{c}\text { Estimate of Mass emitted } \\
\text { from Canberra fires (Tg) }\end{array}$ & $\begin{array}{c}\text { Average Global Annual Emissions (Tg) } \\
\text { Schultz et al. (2008) }\end{array}$ & $\begin{array}{c}\text { \% of average global annual } \\
\text { emissions from Canberra Fires }\end{array}$ \\
\hline $\mathrm{CO}$ & $15 \pm 5$ & 330 & $4.5 \%$ \\
$\mathrm{HCN}$ & $0.05 \pm 0.02$ & Not available & $2.2 \%$ \\
$\mathrm{NH}_{3}$ & $0.11 \pm 0.03$ & 4.90 & $6.3 \%$ \\
$\mathrm{H}_{2} \mathrm{CO}$ & $0.25 \pm 0.07$ & 3.90 & $2.0 \%$ \\
$\mathrm{C}_{2} \mathrm{H}_{2}$ & $0.03 \pm 0.01$ & Not available & $1.4 \%$ \\
$\mathrm{C}_{2} \mathrm{H}_{4}$ & $0.10 \pm 0.03$ & 4.80 & $3.7 \%$ \\
$\mathrm{C}_{2} \mathrm{H}_{6}$ & $0.03 \pm 0.01$ & 2.30 & 3 \\
$\mathrm{HCOOH}$ & $0.21 \pm 0.06$ & Not available & 7.70 \\
$\mathrm{CH}_{3} \mathrm{OH}$ & $0.28 \pm 0.09$ & 7.09 & \\
\hline
\end{tabular}

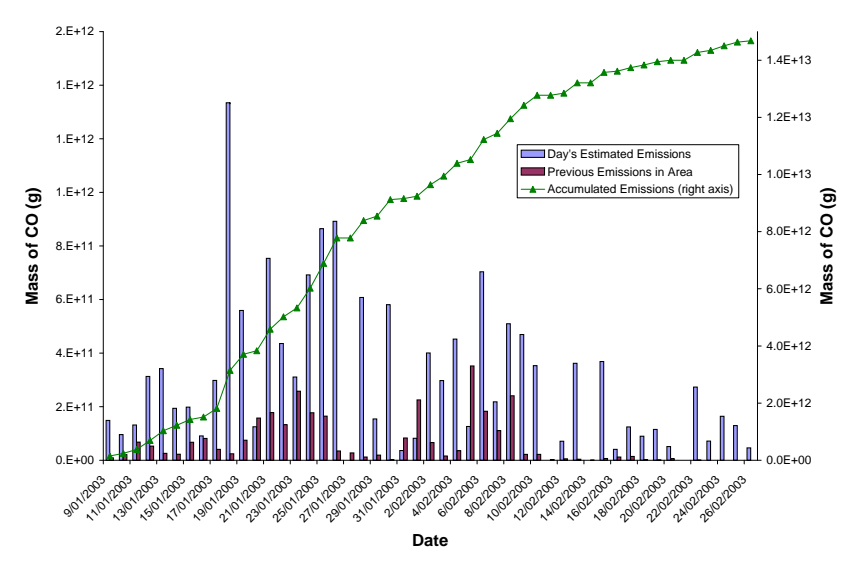

Fig. 3. The estimated emissions of $\mathrm{CO}$ for each day are shown alongside the previous 3 days' emissions that still remain in the area as predicted by MOZART. The accumulated total mass of $\mathrm{CO}$ emitted by the fires is also shown on a separate right-hand axis.

also extracted just for the seven $0.5^{\circ}$ by $0.5^{\circ}$ grid boxes that were used as emissions sources in the MOZART modelling. This gave an estimated total emission of $12.2 \mathrm{Tg} \mathrm{CO}$ from these fires. Van der Werf et al. (2006) do not specify a total uncertainty for the GFED2 emissions inventory but mention a figure of $\pm 20 \%$ for burned area and must also account for uncertainties in fuel loads and emission factors (which are typically in the order of 20-30\% (Andreae and Merlet, 2001)). Thus our estimate of $15 \pm 5 \mathrm{Tg}$ of $\mathrm{CO}$ agrees with the estimate from the GFED2 inventory within the expected uncertainties.

This is a very significant emission from a single fire episode given that the mean global annual emission of $\mathrm{CO}$ from all vegetation fires is estimated as $330 \mathrm{Tg} \mathrm{CO} \mathrm{yr}^{-1}$ for the 41 years from $1960-2000$...(Schultz et al., 2008) and in separate studies for the year 2000 as $496 \mathrm{Tg} \mathrm{CO} \mathrm{yr}^{-1}$ (Ito and Penner, 2004) and $347 \mathrm{Tg} \mathrm{CO} \mathrm{yr}^{-1}$ (Hoelzemann, 2006). Estimates for the total annual CO emissions from Australian vegetation fires in the literature include:
1. between $11-40 \mathrm{Tg} \mathrm{CO} \mathrm{yr}^{-1}$ for the years $1960-2000$, averaging $23 \mathrm{Tg} \mathrm{CO} \mathrm{yr}^{-1}$ (Schultz et al., 2008)

2. $17 \mathrm{Tg} \mathrm{CO} \mathrm{yr}^{-1}$ for 1991 (Hurst et al., 1994)

3. $25 \mathrm{Tg} \mathrm{CO} \mathrm{yr}^{-1}$ for 2000 (Hoelzemann, 2006)

Probably the best comparison is with the study by Schultz et al. (2008), because it covers 41 years from 1960-2000. Our estimate for the Canberra fires is approximately $65 \%$ of the average estimated annual CO emission by Schultz et al. (2008) from all Australian vegetation fires, which also includes burning of savanna grasslands and woodlands in the tropical north of Australia.

Table 2 shows the estimated total emissions from the Canberra fires for all of the trace gases measured at Wollongong by FTIR remote sensing through the smoke plumes (PatonWalsh et al., 2005; Paton-Walsh et al., 2008). Where available, the estimated average global annual emissions of the trace gases from all vegetation fires from Schultz et al. (2008) are also given, along with the percentage of the average global annual emissions that were emitted by the Canberra fires. By this calculation the total formaldehyde released by the Canberra fires represents $6.3 \%$ of the average annual global emission of formaldehyde by vegetation fires. In contrast the ethane released represents only $1.4 \%$ of the average annual global emissions from vegetation fires.

\section{Summary and conclusions}

This paper describes a new technique for estimating trace gas emissions from large vegetation fires. The new method is applied to the Canberra fires of 2003 (from 8 January to 26 February 2003), producing an emissions estimates of $15 \pm 5 \mathrm{Tg}$ of carbon monoxide, which is in agreement with the emissions from the GFED2 inventory (van der Werf et al., 2006). In addition the method produces emissions estimates of $0.05 \pm 0.02 \mathrm{Tg}$ of hydrogen cyanide, $0.11 \pm 0.03 \mathrm{Tg}$ of ammonia, $0.25 \pm 0.07 \mathrm{Tg}$ of formaldehyde, $0.03 \pm 0.01$ 
of acetylene, $0.10 \pm 0.03 \mathrm{Tg}$ of ethylene, $0.03 \pm 0.01 \mathrm{Tg}$ of ethane, $0.21 \pm 0.06 \mathrm{Tg}$ of formic acid and $0.28 \pm 0.09 \mathrm{Tg}$ of methanol released to the atmosphere from these fires. Very similar results are obtained using a simple estimate derived directly from the satellite AOD measurements and so it may be possible to apply this new method without the complication of using a chemical transport model.

The dominant uncertainty in the new method arises from converting from enhanced amounts of aerosol optical depth to enhancements in trace gases. Despite this the use of aerosol optical depth has some benefits over direct satellite measurements of carbon monoxide as it provides greater sensitivity to the boundary layer and is shorter-lived and therefore potentially a better indicator of fresh smoke. There are significant uncertainties in this new technique for estimating trace gas emissions from large vegetation fires, with resulting uncertainties of $\pm 31 \%$. However the uncertainties in this method are largely independent of the uncertainties in conventional methods of estimating emissions from fires, and so we conclude that this new technique is a valuable additional tool for characterising emissions from vegetation fires.

Acknowledgements. The authors would like to acknowledge the support of the Australian Research Council and the Department of Innovation, Industry, Science and Research and for funding this work. The National Center for Atmospheric Research is sponsored by the National Science Foundation. Thanks are also due to the anonymous referees of the ACPD paper and to the MODIS team for providing public access to AOD data, visible images, burn scars and thermal hotspot data.

Edited by: N. Riemer

\section{References}

Andreae, M. O. and Merlet, P.: Emission of trace gases and aerosols from biomass burning, Global Biogeochem. Cy., 15, 955-966, 2001.

Arellano, A. F., Kasibhatla, P. S., Giglio, L., van der Werf, G. R., Randerson, J. T., and Collatz, G. J.: Time-dependent inversion estimates of global biomass-burning $\mathrm{CO}$ emissions using Measurement of Pollution in the Troposphere (MOPITT) measurements, J. Geophys. Res.-Atmos., 111, D09303, doi:10.1029/2005jd006613, 2006.

Chin, M., Ginoux, P., Kinne, S., Torres, O., Holben, B. N., Duncan, B. N., Martin, R. V., Logan, J. A., Higurashi, A., and Nakajima, T.: Tropospheric aerosol optical thickness from the GOCART model and comparisons with satellite and Sun photometer measurements, J. Atmos. Sci., 59, 461-483, 2002.

Chu, D. A., Kaufman, Y. J., Remer, L. A., and Holben, B. N.: Remote sensing of smoke from MODIS airborne simulator during the SCAR-B experiment, J. Geophys. Res.-Atmos., 103, 3197931987, 1998.

Edwards, D. P., Emmons, L. K., Gille, J. C., Chu, A., Attie, J. L., Giglio, L., Wood, S. W., Haywood, J., Deeter, M. N., Massie, S. T., Ziskin, D. C., and Drummond, J. R.: Satellite-observed pollution from Southern Hemisphere biomass burning, J. Geophys.
Res.-Atmos., 111, 17, D14312, doi:10.1029/2005jd006655, 2006a.

Edwards, D. P., Petron, G., Novelli, P. C., Emmons, L. K., Gille, J. C., and Drummond, J. R.: Southern Hemisphere carbon monoxide interannual variability observed by Terra/Measurement of Pollution in the Troposphere (MOPITT), J. Geophys. Res.Atmos., 111, 9, D16303, doi:10.1029/2006jd007079, 2006 b.

Emmons, L. K., Walters, S., Hess, P. G., Lamarque, J. F., Pfister, G. G., Fillmore, D., Granier, C., Guenther, A., Kinnison, D., Laepple, T., Orlando, J., Tie, X., Tyndall, G., Wiedinmyer, C., Baughcum, S. L., and Kloster, S.: Description and evaluation of the Model for Ozone and Related chemical Tracers, version 4 (MOZART-4), Geosci. Model Dev., 3, 43-67, doi:10.5194/gmd3-43-2010, 2010.

Fromm, M., Tupper, A., Rosenfeld, D., Servranckx, R., and McRae, R.: Violent pyro-convective storm devastates Australia's capital and pollutes the stratosphere, Geophys. Res. Lett., 33, 2006.

Hoelzemann, J. J., Schultz, M. G., Brasseur, G. P., Granier, C., and Simon, M.: Global Wildland Fire Emission Model (GWEM): Evaluating the use of global area burnt satellite data, J. Geophys. Res., 109, D14S04, doi:10.1029/2003JD003666, 2004.

Hurst, D. F., Griffith, D. W. T., Carras, J. N., Williams, D. J., and Fraser, P. J.: Measurements of trace gases emitted by Australian savanna fires during the 1990 dry season, J. Atmos. Chem., 18, 33-56, 1994.

Ito, A. and Penner, J. E.: Global estimates of biomass burning emissions based on satellite imagery for the year 2000, J. Geophys. Res.-Atmos., 109, 18, D14S05, doi:10.1029/2003jd004423, 2004.

Kalnay, E., Kanamitsu, M., Kistler, R., Collins, W., Deaven, D., Gandin, L., Iredell, M., Saha, S., White, G., Woollen, J., Zhu, Y., Chelliah, M., Ebisuzaki, W., Higgins, W., Janowiak, J., Mo, K. C., Ropelewski, C., Wang, J., Leetmaa, A., Reynolds, R., Jenne, R., and Joseph, D.: The NCEP/NCAR 40-year reanalysis project, B. Am. Meteorol. Soc., 77, 437-471, 1996.

Kasischke, E. S. and Penner, J. E.: Improving global estimates of atmospheric emissions from biomass burning, J. Geophys. Res.Atmos., 109(9), D14S01, doi:10.1029/2004jd004972, 2004.

Kaufman, Y. J., Tucker, C. J., and Fung, I.: Remote Sensing of Biomass Burning in The Tropics., Journal of Geophysical Research, 95, 9927-9939, 1990.

Kaufman, Y. J.: Aerosol Optical-Thickness and Atmospheric Path Radiance, J. Geophys. Res.-Atmos., 98, 2677-2692, 1993.

Kaufman, Y. J., Tanre, D., Gordon, H. R., Nakajima, T., Lenoble, J., Frouin, R., Grassl, H., Herman, B. M., King, M. D., and Teillet, P. M.: Passive remote sensing of tropospheric aerosol and atmospheric correction for the aerosol effect, J. Geophys. Res.Atmos., 102, 16815-16830, 1997.

Kaufman, Y. J., Justice, C. O., Flynn, L. P., Kendall, J. D., Prins, E. M., Giglio, L., Ward, D. E., Menzel, W. P., and Setzer, A. W.: Potential global fire monitoring from EOS-MODIS, J. Geophys. Res.-Atmos., 103, 32215-32238, 1998.

Kaufman, Y. J., Haywood, J. M., Hobbs, P. V., Hart, W., Kleidman, R., and Schmid, B.: Remote sensing of vertical distributions of smoke aerosol off the coast of Africa, Geophys. Res. Lett., 30, 1831, 713PT, doi:10.1029/2003GL017068 2003.

King, M. D., Kaufman, Y. J., Tanré, D., and Nakajima, T.: Remote sensing of tropospheric aerosols from space: past, present and future., B. Am. Meteorol. Soc., 80, 2229-2259, 1999. 
Kleidman, R. G., O’Neill, N. T., Remer, L. A., Kaufman, Y. J., Eck, T. F., Tanre, D., Dubovik, O., and Holben, B. N.: Comparison of moderate resolution Imaging spectroradiometer (MODIS) and aerosol robotic network (AERONET) remote-sensing retrievals of aerosol fine mode fraction over ocean, J. Geophys. Res.-Atmos., 110, D22205, doi:10.1029/2005JD005760, 2005.

Levy, R. C., Remer, L. A., Mattoo, S., Vermote, E. F., and Kaufman, Y. J.: Second-generation operational algorithm: Retrieval of aerosol properties over land from inversion of Moderate Resolution Imaging Spectroradiometer spectral reflectance, J. Geophys. Res.-Atmos., 112, D13211, doi:10.1029/2006JD007811, 2007.

Paton-Walsh, C., Jones, N., Wilson, S., Meier, A., Deutscher, N., Griffith, D., Mitchell, R., and Campbell, S.: Trace gas emissions from biomass burning inferred from aerosol optical depth, Geophys. Res. Lett., 31, L05116, doi:10.1029/2003GL018973 2004.

Paton-Walsh, C., Jones, N. B., Wilson, S. R., Haverd, V., Meier, A., Griffith, D. W. T., and Rinsland, C. P.: Measurements of trace gas emissions from Australian forest fires and correlations with coincident measurements of aerosol optical depth, J. Geophys. Res.-Atmos., 110, D24305, doi:10.1029/2005JD006202, 2005.

Paton-Walsh, C., Wilson, S. R., Jones, N. B., and Griffith, D. W. T.: Measurement of methanol emissions from Australian wildfires by ground-based solar Fourier transform spectroscopy, Geophys. Res. Lett., 35, L08810, doi:10.1029/2007GL032951 2008.

Paton-Walsh, C., Emmons, L. K., and Wiedinmyer, C.: Australia's 2009 "Black Saturday" Wildfires - Emissions of Trace Gases to the Atmosphere, Geophys. Res. Lett., in preparation, 2010.

Pfister, G., Hess, P. G., Emmons, L. K., Lamarque, J. F., Wiedinmyer, C., Edwards, D. P., Petron, G., Gille, J. C., and Sachse, G. W.: Quantifying CO emissions from the 2004 Alaskan wildfires using MOPITT CO data, Geophys. Res. Lett., 32, L11809, doi:10.1029/2005g1022995, 2005.

Radhi, M., Box, M. A., Box, G. P., Gupta, P., and Christopher, S. A.: Evolution of the optical properties of biomass-burning aerosol during the 2003 southeast Australian bushfires, Appl. Optics, 48, 1764-1773, 2009.

Rasch, P. J., Feichter, J., Law, K., Mahowald, N., Penner, J., Benkovitz, C., Genthon, C., Giannakopoulos, C., Kasibhatla, P., Koch, D., Levy, H., Maki, T., Prather, M., Roberts, D. L., Roelofs, G. J., Stevenson, D., Stockwell, Z., Taguchi, S., Kritz, M., Chipperfield, M., Baldocchi, D., McMurry, P., Barrie, L., Balkansi, Y., Chatfield, R., Kjellstrom, E., Lawrence, M., Lee, H. N., Lelieveld, J., Noone, K. J., Seinfeld, J., Stenchikov, G., Schwartz, S., Walcek, C., and Williamson, D.: A comparison of scavenging and deposition processes in global models: results from the WCRP Cambridge Workshop of 1995, Tellus Ser. BChem. Phys. Meteorol., 52, 1025-1056, 2000.

Remer, L. A., Tanré, D., Kaufman, Y. J., Ichoku, C., Mattoo, S., Levy, R., Chu, D., Holben, B., Dubovik, O., Smirnov, A., Martins, J. V., Li, R.-R., and Ahmad, Z.: Validation of MODIS aerosol retrieval over ocean, Geophys. Res. Lett., 29, 8008(1618), doi:10.1029/2001GL013204, 2002.
Remer, L. A., Kaufman, Y. J., Tanre, D., Mattoo, S., Chu, D. A., Martins, J. V., Li, R. R., Ichoku, C., Levy, R. C., Kleidman, R. G., Eck, T. F., Vermote, E., and Holben, B. N.: The MODIS aerosol algorithm, products, and validation, J. Atmos. Sci., 62, 947-973, 2005.

Rinsland, C. P., Paton-Walsh, C., Jones, N. B., Griffith, D. W. T., Goldman, A., Wood, S. W., Chiou, L., and Meier, A.: High spectral resolution solar absorption measurements of ethylene $\left(\mathrm{C}_{2} \mathrm{H}_{4}\right)$ in a forest fire smoke plume using HITRAN parameters: Tropospheric vertical profile retrieval, J. Quant. Spectrosc. Rad. Trans., 301-309, doi:10.1016/j.jqsrt.2005.03.003, 2005.

Schultz, M. G., Heil, A., Hoelzemann, J. J., Spessa, A., Thonicke, K., Goldammer, J. G., Held, A. C., Pereira, J. M. C., and van het Bolscher, M.: Global wildland fire emissions from 1960 to 2000, Global Biogeochem. Cy., 22(17), Gb2002, doi:10.1029/2007gb003031, 2008.

Singh, H. B., Brune, W. H., Crawford, J. H., Jacob, D. J., and Russell, P. B.: Overview of the summer 2004 intercontinental chemical transport experiment - North America (INTEX-A), J. Geophys. Res.-Atmos., 111(17), D24S01, doi:10.1029/2006jd007905, 2006.

Tanre, D., Kaufman, Y. J., Herman, M., and Mattoo, S.: Remote sensing of aerosol properties over oceans using the MODIS/EOS spectral radiances, J. Geophys. Res.-Atmos., 102, 16971-16988, 1997.

van der Werf, G. R., Randerson, J. T., Giglio, L., Collatz, G. J., Kasibhatla, P. S., and Arellano Jr., A. F.: Interannual variability in global biomass burning emissions from 1997 to 2004, Atmos. Chem. Phys., 6, 3423-3441, doi:10.5194/acp-6-3423-2006, 2006.

Webb, R., Davis, C. J., and Lellyett, S.: Meteorological aspects of the ACT bushfires of January 2003, Bushfire 2004 Conference, Dept. for Environment and Heritage, Adelaide, Australia, 2004.

Williams, J., de Reus, M., Krejci, R., Fischer, H., and Strm, J.: Application of the variability-size relationship to atmospheric aerosol studies: estimating aerosol lifetimes and ages, Atmos. Chem. Phys., 2, 133-145, doi:10.5194/acp-2-133-2002, 2002.

Young, E. and Paton-Walsh, C.: Formaldehyde and nitrogen dioxide in smoke plumes from Australia's Black Saturday fires, Australian Meteorological and Oceanographic Society, Canberra, Australia, 2010,

Zhao, T. X. P., Laszlo, I., Dubovik, O., Holben, B. N., Sapper, J., Tanre, D., and Pietras, C.: A study of the effect of non-spherical dust particles on the AVHRR aerosol optical thickness retrievals, Geophys. Res. Lett., 30, 1317, doi:10.1029/2002GL016379, 2003. 